\title{
NIETZSCHE CONTRA WAGNER: ¿MÚSICA COMO SIMULACIÓN? ${ }^{1}$
}

\author{
Claus-Artur Scheier
}

Universidad de Braunschweig

RESUMEN: Las teorías de Wagner sobre la música influyeron grandemente en la estética de Nietzsche. No sólo cuando fue seguidor de ellas, en su época wagneriana, sino también en su madurez cuando desarrolló su crítica radical a Wagner y al ideal estético que representaba. Para bien y para mal, Wagner le enseñó a Nietzsche una nueva concepción de la música, y del arte en general, en la que éstos se fundamentan en última instancia en el «gesto». El trabajo hace un recorrido por la trayectoria intelectual de Nietzsche, recurriendo ampliamente a los escritos de Wagner, para corroborar esta tesis.

Palabras clave: arte - música - estética

ABSTRACT: Wagner's theories on music greatly influenced Nietzsche's aesthetics. Not only when he was a follower of these theories, in his Wagnerian period, but also in his maturity, when he developed his radical critique of Wagner and of the aesthetic ideal that he represented. For good and for ill, Wagner taught Nietzsche a new conception of music, and of art in general, in which both are ultimately based on "gesture». This paper looks at Nietzsche's intellectual journey, referring widely to the writings of Wagner, to corroborate this thesis.

Keywords: art - music - aesthetics

Charles Baudelaire escribió a Richard Wagner que le debía el mayor deleite musical que jamás había experimentado², y en su ensayo Richard Wagner et Tannhäuser à Paris, aparecido en 1861 con ocasión de las representaciones parisinas de Tannhäuser, rodeadas de escándalo, leemos que Wagner es, «actualmente, en virtud de la energía apasionada de su expresión, el representante más verdadero de la naturaleza moderna $»^{3}$. De lo que no cabe duda, prosigue, es de que «su doc-

1. La presente traducción está basada en un texto leído como conferencia en Valencia en octubre de 2003. La conferencia fue revisada en 2005 para su publicación en alemán con el título: «Die Geburt der Musik aus dem Geist der Gebärde oder Was Nietzsche von Wagner gelernt hat» [El nacimiento de la música a partir del espíritu del gesto o qué aprendió Nietzsche de Wagner], en C. Lütge y T. L. Meyer (eds.), Musik-Technik-Philosophie. Fragen und Positionen, Freiburg/München, 2005. Agradecemos la autorización y las indicaciones del autor para la traducción y publicación castellana de la conferencia. Para un tratamiento más detallado del problema, cf. C.-A. Scheier, Ästhetik der Simulation. Formen des Produktionsdenkens im 19. Jahrhundert, Hamburg, 2000.

2. «Avant tout, je veux vous dire que je vous dois la plus grande jonissance musicale que j'aie jamais éprouvée» (carta del 17 de febrero de 1860).

3. «[...] par l'énergie passionnée de son expression il est actuellement le représentant le plus vrai de la nature moderne». 
trina es idónea para reunir a todas las cabezas ingeniosas que desde hace mucho tiempo están hartas de las equivocaciones de la ópera» ${ }^{4}$. En resumidas cuentas: «La ópera de Wagner es una obra seria que exige una atención constante» ${ }^{5}$; una exigencia inaudita no sólo para el público de ópera europeo, y no digamos para el público de París, sino incluso para el mismo Baudelaire, quien había aprendido en el ensayo Philosophy of Composition de Edgar A. Poe, que él mismo tradujo en 1859, que «todas las excitaciones intensas, por necesidad psíquica, son cortas» ${ }^{6}$, y que el efecto buscado por medio de una obra más larga sólo se puede conseguir de modo intermitente.

No es de extrañar, por tanto, que Baudelaire calificase en más de una ocasión la música de Wagner de «despótica». Precisamente la poesía de Poe representaba para él la «naturaleza moderna» de manera ejemplar; pero si ahora veía en Wagner a su más verdadero representante, es porque había reconocido que con esta música había entrado algo nuevo en el mundo moderno: si en la obra de arte, según la acuñación de Poe, la vida toma en serio el arte, aquí se invierte dicha relación, y es el arte el que toma en serio la vida, es decir - y de esto no deja duda el perspicaz ensayo de Baudelaire-, el arte mismo se convierte en religión y no tolera ya en el futuro ninguna otra religión a su lado.

A esta comprensión de Baudelaire de la seriedad despótica de este arte puede referirse Nietzsche, diez años después, en el prólogo a Richard Wagner que sirve como preludio a El nacimiento de la tragedia desde el espíritu de la música:

Usted recordará entonces que yo me concentré en estos pensamientos al mismo tiempo en que surgía su magnífico escrito conmemorativo sobre Beethoven, es decir, en medio de los horrores y sublimidades de la guerra que acababa de estallar. Sin embargo, errarían quienes acaso pensasen, a propósito de esa concentración, en la antítesis entre excitación patriótica y disipación estética, entre seriedad valiente y juego jovial: a éstos, si leen realmente este escrito, acaso les quede claro, para estupor suyo, con qué problema seriamente alemán tenemos que habérnoslas, el cual es situado por nosotros con toda propiedad en el centro de las esperanzas alemanas, como vértice y punto de viraje.

Nietzsche no hablará más de aquellas «sublimidades» en cuanto se dé cuenta de lo que en realidad había de suceder con el «imperio» y que incluso la obra de arte de Wagner era cualquier cosa menos un simple problema alemán. Para Baudelaire había sido ya un acontecimiento europeo, y sólo con el alejamiento de Wagner, el pensamiento de Nietzsche alcanzará la altura de la problemática moderna expuesta por Baudelaire. Pero aquí Nietzsche ya está de acuerdo con él en que ha tocado a su fin la época en que, en la estela de Schiller, se mantiene la separación entre la seriedad de la vida y el juego del arte, y con la esperanza de que aquellos que todavía abogan por tal separación queden asombrados a la vista de su problema, el filólogo clásico marca con suficiente claridad un nuevo comienzo de la filosofía. «Torbellino y punto de inflexión» es este problema: dinos (dinē)

4. «Ce qui est bien certain, c'est que sa doctrine est faite pour rallier tous les gens d'esprit fatigués depuis longtemps des erreurs de l'Opéra».

5. «[...] l'opéra de Wagner est un ouvrage sérieux, demandant une attention soutenue» (subrayado de Baudelaire).

6. «[...] all intense excitements are, through a psychical necessity, brief». 
kai peripeteia, aludiendo a su fuerza trágica conformadora de mundo; pues el torbellino era principio cosmogónico en la temprana filosofía griega, cuya esencia «trágica» es movilizada en El nacimiento de la tragedia contra el optimismo socrático invertido en pesimismo o, como más tarde dirá Nietzsche, convertido en nihilismo. Ya en «Sócrates y la tragedia griega» había destacado Nietzsche que uno no puede «negarse a ver en Sócrates un punto de inflexión y un torbellino de la llamada historia universal»; una formulación que se encuentra también en el apartado 15 de El nacimiento de la tragedia, mientras que en el esbozo del prólogo se hablaba sólo del «torbellino del ser». La oposición Sócrates-Wagner, por tanto, es muy conscientemente llevada a escena.

Que ahora Nietzsche, al principio de su camino de pensar, crea haber encontrado la peripecia de la Modernidad en la obra de Wagner, aparentemente le pone de acuerdo con Baudelaire, pero, en cuanto ve ahí un «problema seriamente alemán", se despide por de pronto del horizonte estético de Baudelaire. A Nietzsche, que se vio a sí mismo durante toda su vida, igual que a su maestro filosófico Schopenhauer, como un «educador», también en el caso de Wagner le importa esencialmente el educador, cuyo credo estético-político se hallaba disponible desde 1870 en el escrito sobre Beethoven. Dicho escrito proyecta, en forma de una «filosofía de la música», el camino por el que tiene que "conducir el espíritu alemán a su pueblo», «si debe hacer felices a los pueblos conforme está llamado a hacerlo». Cuando Nietzsche escriba, en el tardío «Ensayo de autocrítica», que se arruinó a sí mismo «el grandioso problema griego, como me fue dado comprenderlo, por la intromisión de las cosas más modernas», no estará pensando solamente en la filosofía de Schopenhauer, sino más aún en la visión del mundo de Wagner.

Como en un palimpsesto esta visión del mundo trasparece por doquier en el primer escrito filosófico de Nietzsche, y aunque éste cuestionará, también públicamente, con creciente radicalidad su valoración del significado histórico de Wagner a partir de Richard Wagner en Bayreuth (1876), nunca abandonará la comprensión originaria de Wagner de que una estética verdaderamente contemporánea debe ser al mismo tiempo religión y, como tal, necesariamente política. Desde el principio se dio cuenta de que el Beethoven inventado por Wagner era el protagonista de una nueva política alemana, cuyo Vaticano se llamaba Bayreuth: «Pues lo que oís, es Roma - iLa fe de Roma sin palabras!», así termina el capítulo octavo, «Pueblos y patrias», de Más allá del bien y del mal.

En esos momentos importaba enseguida crear escuela para esta estética político-religiosa. Su manifiesto es El nacimiento de la tragedia, y la referencia al «magnífico escrito de homenaje a Beethoven» de Wagner tiene un carácter enteramente programático. Pues en ese escrito se articula la visión del mundo de Wagner después del «giro» de Feuerbach a Schopenhauer, acontecido cuando Wagner estaba trabajando en el tercer acto de Sigfrido y en los primeros esbozos de El ocaso de los dioses. ¿De qué manera corresponde este tardío testimonio de la agitación wagneriana a los ambiciosos proyectos de Nietzsche? ¿O no lo hace en realidad, y Nietzsche se equivocó con Wagner, como él mismo creyó reconocer muy pronto, a saber, ya durante la redacción de Richard Wagner en Bayreuth ${ }^{7}$ ?

7. Que el pensamiento de Nietzsche, desde el principio, estaba en curso de colisionar con la visión del mundo de Wagner, ha sido hace poco convincentemente mostrado por D. Sánchez Meca, «El adversario interior»: Estudios Nietzsche 1 (2001), 119-144. 
En los primeros párrafos de su escrito sobre Beethoven, Wagner desarrolla «la diferencia total del poeta respecto del músico», que no está creando, como el poeta, en «una figuración consciente», sino desde «el fondo oscuro de su inconsciente». Ésta es la diferencia entre superestructura y base, que no es pensada económicamente como en Marx, sino estéticamente, por lo que a Wagner le interesa enseguida la productividad como tal — vinculada a la individualidad del artista—: su Beethoven se agrupa con aquellos autotestimonios artísticos en los cuales se refleja, como en Poe y en Baudelaire, la esencia productiva del hombre de la naciente edad industrial, liberada por una ruptura estética de la atadura de la metafísica.

Pero que el asunto más auténtico de un pensamiento genuinamente contemporáneo -y, por lo tanto, en vista del historicismo reinante, de un pensamiento «intempestivo»- tenía que ser la productividad humana misma, eso es lo que Nietzsche efectivamente aprendió de Wagner y no ya de sus griegos. El encuentro con Wagner liberó no sólo al pensador Nietzsche del filólogo, sino que liberó también al pensador radicalmente moderno, el cual comprendió que el admirado Schopenhauer, sin menoscabo de su polémica antiidealista que despojó al naciente siglo XIX de dos milenios y medio de metafísica, se había apartado al mismo tiempo de este siglo XIX al negar la nueva esencia del hombre, la productividad ya no natural, sino técnica («artificial») bajo el concepto sólo aparentemente natural de la «voluntad para la vida».

La negación de la voluntad para la vida y para la vida ascética, o la afirmación de la voluntad para la vida y la reproducción interminable y sin sentido del dolor y del aburrimiento: ésta era la alternativa de Schopenhauer. Y, por cierto, esta alternativa existencialista, aparentemente, no se presenta en el Wagner «schopenhaueriano», de manera que Nietzsche, por ejemplo, en el aforismo 99 de La gaya ciencia, puede advertir:

Nada va tanto contra el espíritu de Schopenhauer como, precisamente, lo propiamente wagneriano en los héroes de Wagner: me refiero a la inocencia de la suprema egolatría, la fe en la gran pasión como lo bueno en sí, en una palabra: lo propio de Sigfrido en la frente de sus héroes. «Todo eso huele más bien a Spinoza que a mí», diría quizás Schopenhauer.

Wagner siguió siendo un feuerbachiano invertido. Por cierto, él se despide en el principio de la filosofía de Schopenhauer - y prepara con ello la «inversión» nietzscheana de Schopenhauer- porque le importa el regreso no a la «nada», sino a una producción originaria, es decir, que no está alienada por el producto moderno, la llamada por Wagner «moda». Donde Schopenhauer había negado la voluntad para la vida, allí Wagner afirma la voluntad para la producción. Pero como esta voluntad, por otro lado, no va dirigida esencialmente a la producción prospectiva («utópica») (como en Marx a la forma comunista de producción o, en Nietzsche, al crear dionisíaco), sino que esta producción ya produce, incluso político-estéticamente, o simula como si fuese actual, el pensamiento de Wagner evoluciona al mismo tiempo regresivamente, y se da un aspecto ideológico: «si queremos imaginarnos un verdadero paraíso de productividad, propio del espíritu humano, entonces tenemos que trasladarnos a los tiempos de antes del descubrimiento de la escritura y su fijación en el pergamino o en el papel. Tenemos que darnos cuenta de que aquí nació toda la vida cultural». 
La retirada del mundo de los productos modernos y de su estética mercantil se desvía, de manera diferente que en Poe y Baudelaire, de la producción contemporánea hacia una naturaleza humana afirmada como históricamente originaria o prehistórica. En aquel verdadero paraíso «la poesía, ciertamente, no era otra cosa que una auténtica invención de mitos, [...] en los cuales se reflejaba la vida humana [...] con objetiva realidad en el sentido de inmediatas apariciones de espíritus». Estos mitos no tienen la determinación, propia del romanticismo primitivo, de ser aparición del fundamento de la vida humana, sino que son su reflejo (duplicación: reproducción en otro medio), de la misma manera que el arte schopenhaueriano era reflejo de las llamadas ideas platónicas, del modelo en el «velo de la Maya»; sólo que con la diferencia de que el arte para Schopenhauer significó, consecuentemente, el mero paso a la renuncia del mundo, mientras que Wagner mantiene el mundo como originariamente positivo: «La capacidad para eso la vemos como propiedad de cualquier pueblo de noble casta, hasta el momento en que llega a él el uso de la escritura. A partir de ahí desaparece para él la fuerza poética».

Tenemos aquí por consiguiente, in nuce, una historia de la cultura como historia de la decadencia: los pueblos nobles por naturaleza son originalmente (prehistóricamente) productivos en la creación de mitos como base lingüística de toda su vida cultural, la cual, finalmente, es disuelta no por el invento sino por la adopción de la escritura. Esto equivale a insinuar que a un "pueblo de casta noble» no se le cree capaz de hacer tal invención, sino que solamente «llega a ella» a través de pueblos de otra casta. Y en este momento empieza la historia y, enseguida, como decadencia. Su segundo estadio lo alcanza en el «salto de la escritura al arte de imprimir», y, correspondientemente, la verdadera Reforma para Wagner es esencialmente obra de la música: «Se puede suponer que solamente el magnífico coral de Lutero salvó el sano espíritu de la Reforma, porque determinó la mente y sanó, con ello, la enfermedad de los cerebros a causa de la letras».

A continuación viene el tercer y último estadio: «[...] con el invento de los periódicos, a partir del pleno florecimiento del periodismo, este buen espíritu del pueblo tuvo, sin embargo, que retirarse por completo de la vida. Pues ahora solamente reinan opiniones, a saber, 'públicas'; éstas se pueden obtener por dinero, como las mujeres públicas». Con lo que queda abierta la oposición después pensada existencial-analíticamente por Heidegger en Ser y tiempo entre autenticidad e inautenticidad (Man) como oposición entre lengua (mitopoética) y prensa. Y Wagner piensa desde el principio conforme a su concepto de pueblo: «Así, el periódico de moda de París dice también a la 'mujer alemana' cómo tiene que vestirse; pues para decirnos qué es lo correcto en tales cosas, el francés ha adquirido pleno derecho, ya que se ha erigido en auténtico ilustrador multicolor de nuestro mundo de papel de periódico».

Curiosamente, fue nada menos que Stéphane Mallarmé quien, cuatro años después del escrito de Wagner, editó ocho números de un periódico de moda con el título La dernière mode y en gran parte los redactó él mismo; pero la moda francesa representa para Wagner algo más que un mero índice de la Modernidad. Es para él el histórico «uno» (Man) mismo, el «se», como lo deja ver el paralelismo con la historia de la decadencia de los pueblos. Ésta empieza con «el mundo plástico de la Antigüedad griega» que había «conquistado para sí la prerrogativa» 
—una frase que resonaba en los oídos de Nietzsche — de «instruirnos para todos los tiempos acerca de cómo el curso restante de la vida del mundo podría aún configurarse de modo que fuera soportable». De manera significativa, Wagner no habla de la Edad Media, a la que debe la mayoría de sus temas, y empieza a hablar de los italianos del Renacimiento y de sus sucesores: «Vemos cómo este pueblo, tan altamente dotado con una tan rica fantasía, se consume totalmente en el cuidado apasionado de aquella doctrina [griega]; tras un siglo maravilloso sale como un sueño de la historia, la cual desde entonces se apodera, erróneamente, de un pueblo que parece familiar».

Luego, después de la «noche de san Bartolomé» («bodas de sangre de París») y sus consecuencias, se procede «con el resto de la nación» «de una manera 'artística'; pero como le faltaba, o se le había agotado, toda fantasía, la productividad no quiso mostrarse por ningún lado y, particularmente, permaneció incapaz de crear una obra de arte». Sin embargo, precisamente esta improductividad radical convierte a los franceses en el «pueblo dominante de la actual civilización», en el hombre moderno por antonomasia; y, de este modo, no es «un capricho casual de nuestra vida pública que estemos bajo el dominio de la moda; de la misma manera como está fundado inequívocamente en la historia de la civilización moderna que los caprichos del gusto parisiense nos dicten las leyes de la moda».

La moda es, por eso, el producto necesario de una historia de decadencia de la productividad originaria y, en cuanto Modernidad sin más, es «la forma externa de la sociedad». "Se pone a su disposición, en la necesidad permanente de novedad, el cambio de los extremos como única recomendación». Y al tener este cambio sin centro la determinación de un destino, tenemos que «darnos cuenta por fin de que estamos entregados a una maldición verdadera, de la cual sólo nos podría salvar un inicio nuevo, fundado de manera infinitamente profunda». Esta comprensión es para Wagner, al mismo tiempo, la que muestra que la decadencia de los pueblos no es tan radical como para que hubiese podido corromper totalmente al pueblo alemán. Pues el «genio» de éste, que «desde el florecimiento del mundo periodístico [...] tuvo que retirarse de la vida», tiene, como productividad reprimida en lo más interno, la forma del sentimiento indignado. Por eso Wagner puede afirmar que «otra vez nuestro sentimiento se rebela contra aquel dominio", ya que, "mientras las armas alemanas avanzan victoriosamente hacia el centro de la civilización francesa, se remueve en nosotros de repente el sentimiento de vergüenza por nuestra dependencia de esta civilización».

Esto, por cierto, significa que el anhelo por aquel «inicio nuevo, fundado de manera infinitamente profunda», acaba en una transformación originaria de la esencia alemana, a saber, en su despedida histórica de la Modernidad - y, de esta manera, de la escrituralidad en general-: «Todo nuestro ser fundamental debería transformarse de tal forma que el concepto de moda mismo tuviese que llegar a ser totalmente carente de sentido para la conformación de nuestra vida exterior». Pero la oportunidad de poder esperar este nuevo inicio precisamente del pueblo alemán, Wagner la lee en la historia de manera circular:

Pero al lado de este mundo de la moda nos [a los alemanes] nació simultáneamente otro mundo. Igual que bajo la civilización universal de los romanos surgió el cristianismo, así irrumpe ahora la música desde el caos de la civilización moderna. Ambos declaran: «Nuestro reino no es de este mundo». Esto significa justamente: 
nosotros venimos de dentro, vosotros de fuera; nosotros procedemos de la esencia, vosotros de la apariencia de las cosas.

De esto se deduce que aquel mitopoético "paraíso de la productividad» antes de la invención de la escritura era, en realidad, el paraíso de la música. Y el garante de este «reino», que «no es de este mundo», a saber, no de este mundo en general, sino del mundo de la Modernidad (francesa), es ahora, después de Lutero, Beethoven. Pero que Beethoven, que «devolvió a la música su alma inmortal», no pudo originar el esperado "nuevo inicio» y la transformación de toda la esencia fundamental alemana, no es sólo un hecho histórico reconocido por Wagner, sino que convierte a Beethoven, ante todo, en promotor y primer santo de la nueva religión, que tiene que ser fundada por el "festival escénico» (Anillo) y por el «festival escénico sagrado» (Parsifal) wagnerianos:

Nos debe parecer cierto que nuestra civilización [...] sólo puede ser inspirada nuevamente a partir del espíritu de nuestra música, de la música que Beethoven liberó de las ataduras de la moda. Y la tarea de completar en este sentido la nueva civilización, más inspirada, que de esta manera acaso se esté configurando, con la nueva religión que la penetra, esta tarea sólo puede incumbir, evidentemente, al espíritu alemán [...].

En este espíritu se vuelve Wagner a la «observación del mundo exterior», «bajo cuya presión ese ser interior se hace capaz de esa fuerza, ahora propia de él, que reacciona hacia fuera». Aquí, la capacitación frente a la Modernidad que produce sufrimiento, se muestra como una reacción hacia fuera que, a su vez, es consecuencia de una reacción hacia dentro, a saber, de una reacción de autocapacitación del sentimiento indignado: esta doble reacción se propone contra la «apariencia», contra el mundo efectivamente real, como actuar originario, como «esencia». Wagner apenas si podía describir más acertadamente el resentimiento enseguida diagnosticado por Nietzsche y su núcleo ideológico.

Esta autocapacitación, no obstante, se entiende siempre en Wagner en un sentido político-estético. El acto «inaudito» de Beethoven es, por eso, el adelantarse a la «forma de arte más perfecta» en la que la Modernidad en cuanto moda, y esto significa en cuanto «convencionalidad, quedaría totalmente asumida». Tomada al pie de la letra sería, por eso, lo nuevo por antonomasia, aquello que Heidegger llamará, en la conferencia «El giro», «el relámpago de la verdad del ser en el ser carente de verdad». Pero esto nuevo por antonomasia sería, como forma de arte, asimismo lo completamente incomprensible, que ya ni siquiera podría ser reconocido como obra de arte, dicho con palabras de Baudelaire: lo inmutable (l'immuable) sin lo fugitivo (le fugitif). Naturalmente, la sustancia sin accidentes es ella misma lo fugitivo por antonomasia, en donde se desvela el núcleo utópico de la obra de arte wagneriana: es el proyecto de la obra de arte puesto en obra con los medios del arte, es decir, otra vez el discurso cosmovisional en la apariencia de su otro, a saber, del objeto proyectado de este discurso. Nietzsche llamó a Wagner por eso el «Cagliostro de la Modernidad».

Pero no basta con esta reciprocidad interna, que caracteriza quizás la obra de arte moderna. La paradoja que propiamente hay que enlazar con el nombre de Wagner radica más bien en que esta obra de arte, al seguir siendo obra de arte, es al mismo tiempo la ideología puesta en el producto. Porque la forma de arte 
totalmente alejada de toda convencionalidad debe, por un lado, ser «meramente humana», pero, por otro lado, ser aquella «que originalmente [...] pertenece al espíritu alemán». Sin embargo, para que este espíritu pueda mostrarse como alemán, debe ser capaz de apelar a una diferencia socio-histórica que caracteriza a cada uno de sus portadores, es decir, apelar justamente a una convencionalidad, aunque sea una convencionalidad «natural», como insinúa necesariamente el título de «pueblo» en el siglo XIX.

Por lo tanto, lo que es puramente humano no debe ser puramente alemán en un sentido idealista (por ejemplo, en el sentido de Fichte), sino que es sólo ideológicamente como lo puramente alemán es puramente humano. Y si el espíritu alemán "debe hacer felices a los pueblos, como está llamado a hacerlo», entonces no debe agraciarles con lo puramente humano sino consigo mismo. Es decir, este espíritu alemán de 1870 reacciona al dominio de la Modernidad, que siente como dominio imperial, con la propia reivindicación imperial y su autocapacitación: dominio de «la profundidad y de la intimidad» contra el dominio de la moda. Pero al significar dominio siempre convencionalidad, una profundidad e intimidad dominante, la "pura» sustancia sin accidentes, es una contradictio in adiecto, y en cuanto contradicción que se oculta, por tanto, ideología, exactamente lo que Wittgenstein describirá como «proposición metafísica»: el sinsentido con apariencia de sentido.

Debe quedar seguramente sin aclarar si Wagner se dio cuenta de que negó de raíz el pensamiento de Schopenhauer, aunque por doquier usara su terminología. Schopenhauer fue, para decirlo así, nada más que el catalizador de su transformación de la herencia feuerbachiana, que puso al pueblo alemán y su espíritu en el lugar del yo y el tú. Y con ello la voluntad, afirmada originariamente ya en Feuerbach, ya no es más la antigua voluntad de la vida, sino, en cuanto voluntad de la producción político-mitopoética, una voluntad nueva, hasta ahora no pensada, a saber, la voluntad de poder:

Esta inmensa inundación de todas las barreras de la aparición debe causar necesariamente en el músico entusiasmado un éxtasis, con el cual no se podría comparar ningún otro: en él se reconoce la voluntad como voluntad todopoderosa: no tiene que abstenerse mudamente de la intuición, sino que en voz alta se anuncia a sí mismo como idea consciente del mundo.

Esta identificación del músico con la voluntad todopoderosa del mundo es el pensamiento de Bayreuth y la autolegitimación de la ideología alemana de Wagner, al dejar surgir inmediatamente la segunda identificación de lo "puramente humano» con el «espíritu alemán». Pues bajo las condiciones de la civilización presente, este delirio productivo es siempre sólo de corta duración y lleva a un estado de la conciencia que Wagner califica como «deplorable», y que Nietzsche vio después en la obra de Brahms como «la melancolía de la incapacidad», que en Brahms sin embargo no sobrepasa el «anhelo». Pero «al igual que cincuenta pasos más allá de Brahms uno encuentra a Wagner», se encontrará, cincuenta pasos más allá del anhelo de Brahms, el resentimiento de Wagner.

Su empuje radica precisamente en que en Wagner la forma técnica de producción, o la producción de mercancías, ya no tienen, como hasta ahora, sus reflejos estéticos en la existencia individual. Son ahora aceptadas como la cons- 
titución existencial del mundo, aunque no comprendidas como tales, como en el caso de Marx, y por ello hipostasiadas, es decir, ideologizadas, casi metafísicamente como el «espíritu» de un «pueblo», del pueblo alemán. Esto sería, por cierto, un estadio sumamente instructivo para la historia de la producción técnica en su forma de producción estética, pero no obstante no hubiese pasado de un intermedio histórico, si el correlato histórico-real de esta visión del mundo, a saber, el Estado alemán, hubiese conseguido constituir una forma de sociedad correspondiente al estado de los medios de producción en la segunda mitad del siglo XIX, como, por lo menos, los vecinos franceses e ingleses habían conseguido, sin importar bajo qué desafortunados augurios. Hubiese; de modo que la «sabiduría» de Nietzsche, perspicaz todavía en el año 1889 en que se anuncia la locura, ya no se sabía expresar de otra forma que maldiciendo a su vez:

El príncipe Bismarck ha aniquilado, en favor de su política doméstica, con una seguridad del instinto digna de maldición, todas las presuposiciones para las grandes tareas, para los fines histórico-universales, para una espiritualidad más noble y refinada. Y mirad a los alemanes mismos, tal vez la raza más baja, estúpida y vulgar que está actualmente sobre la tierra, "hohenzollernizada» hasta el odio contra el espíritu y la libertad.

Antes, en El caso Wagner, Nietzsche había seguido esta fatalidad hasta su origen estético y había exigido: «iQue el teatro no se apodere de las artes! / iQue el artista no se convierta en seductor de lo auténtico! / iQue la música no se convierta en el arte de mentir!». Para el pensar de Nietzsche, el tertium comparationis entre aquel grito de desesperación y esta exigencia aparentemente sólo estética, es el discurso de Zaratustra sobre el último hombre y, con ello, exactamente el mismo problema contemporáneo. En el quinto libro de La gaya ciencia Nietzsche había escrito:

La música como medio para la clarificación, el fortalecimiento, la interiorización del gesto dramático y de la adicción de los actores a sus sentidos; iy el drama wagneriano sólo como la oportunidad para muchos caprichos dramáticos! Él tenía, junto con todos los demás instintos, los instintos directores de un gran actor, en todas y cada una de las cosas: y, como ya se ha dicho, también en cuanto músico.

Nadie sabía mejor que Nietzsche que estos «instintos directores» eran de naturaleza estético-política. Porque en Wagner el individuo que tenía que ser redimido, como lo había pensado Schopenhauer, había sido sustituido por el colectivo productivo pero de otra manera que, por ejemplo, en Marx, no en la forma de una clase social-realmente productiva, sino de una ficción cosmovisional. Pues este pueblo alemán es una ficción, ya por el hecho de que las figuras históricoconcretas del alemán, el Estado alemán o los Estados alemanes, por un lado, y la comunidad lingüística alemana, por el otro, ante la música como «esencia», recaen en la mera «apariencia de las cosas». De esta manera, sólo quedan las ideas del biologicismo, propias de la época, y esto es también una de las muchas raíces del antisemitismo wagneriano que, por el contrario, transformó a Nietzsche en un anti-antisemita. En el otoño de 1887, escribe que no se ha dejado «engañar por un venenoso movimiento contrario, que es el que manda ahora».

El «espíritu» de este pueblo wagneriano, sin embargo, sólo puede «hacer 
felices a los pueblos» presentándose en la figura de un líder (Führer), y como en calidad de espíritu del pueblo alemán es al mismo tiempo el «alma de la música» misma, este líder - y, hay que destacarlo, en esto la visión del mundo wagneriana se mantiene totalmente en el ámbito artístico- solamente puede ser un músico.

Ninguna otra persona que no fuera el propio maestro de Bayreuth es el verdadero mediador entre la voluntad todopoderosa del alma musical del mundo y su pueblo. Y la estética de la producción musical, que Wagner presenta con su Beethoven, es al fin la legitimación de esta propiamente autocapacitación religiosa, la cual al mismo tiempo no quiere ser "de este mundo", porque el arte del músico «se comporta en verdad en relación con el complejo de todas las demás artes como la religión con la iglesia». La pregunta que mueve a esta estética de la producción, que en esta medida se distingue radicalmente de todas las estéticas de artista hasta ahora conocidas, ya no es, por lo tanto, la pregunta clásica acerca de las reglas en virtud de las cuales una obra de arte es bella o sublime, ni tampoco, como por ejemplo en Poe y Baudelaire, acerca del modo en que actúa sobre el individuo, sino de cómo actúa sobre un pueblo elegido por la historia, el pueblo alemán.

Nietzsche había percibido este mensaje, pero desde la mitad de los años setenta había empezado también a comprender que aquella pretensión estético-política de liderazgo no iba dirigida en absoluto, como había esperado El nacimiento de la tragedia, a la renovación del paraíso verdadero conjurado por Wagner, el paraíso de la productividad del espíritu humano, sino más bien a la puesta en escena de su sucedáneo; de ahí su preocupación de "que el actor no se convierta en seductor de los auténticos».

Lo que ya había fascinado a Baudelaire en la obra de arte wagneriana eran los paradis artificiels, que no obstante, ya no son producidos de manera natural por el alcohol, el hachís y el opio, sino de manera verdaderamente artificial, a saber, "contra el orden de las leyes naturales", como un mundo que sólo por eso queda a la vista de todos, «el mundo del más claro conocimiento y de la capacidad suprema»; como la simulación de la productividad, frente a la cual el mundo exterior de las «cosas», a saber, el mundo de los productos (industriales), es ahora un mundo de la «equivocación». En este sentido, la obra de arte de Wagner no sólo está a la altura de los productos técnicos de su tiempo, sino que los supera haciendo que sean olvidados en la alucinación (como también se tiene que procurar ahora que «los movimientos mecánicos de los músicos, el aparato auxiliar de una producción orquestal, que se mueve de manera completamente singular», sea sustraído a los ojos de los espectadores en el foso de la orquesta, así como las fábricas contemporáneas, similares a "palacios de hadas», desaparecen detrás de fachadas neogóticas).

«En Wagner está al principio la alucinación: no la de los sonidos, sino la de los gestos», había reconocido Nietzsche; y que la música es el intérprete original del gesto, y no viceversa, Wagner lo explica en Beethoven de este modo: la música expresa «la esencia más interior del gesto con una comprensibilidad tan inmediata que ella, en cuanto la música nos llena por completo, incluso incapacita a nuestra vista para la intensa percepción del gesto, de manera que lo entendemos por fin sin verlo». Pero el gesto, la «actitud» de Nietzsche, es, en cuanto cuerpo momentáneamente convertido en signo, ya «escritura», producto, 
y así más bien sustituto de una producción originaria. Nietzsche lo vio y sacó una conclusión - también necesariamente hiperbólica- que naturalmente no quiso tener en cuenta el "pueblo» de Wagner, al preferir un Nietzsche wagnerizado a un Wagner comprendido.

Cuando, por eso, Martin Gregor-Dellin escribe en su Crónica de Wagner (Múnich, 1972), con fecha «20 de julio a 7 de septiembre de 1870»: «Wagner está trabajando en su escrito Beethoven, que cuenta con la aprobación de Nietzsche, y en el que defiende la supremacía de la música sobre el texto", hay que añadir que la música de Wagner, por su parte, está bajo la supremacía del gesto. En cuanto éste, a su vez, tiene carácter de escritura, se demuestra que la polémica «fonocéntrica» de Wagner contra la escrituralidad histórica surgió más bien del intento político-estético de representar la «escritura originaria» (archi-écriture) como el programa de una productividad mitopoética.

Jacques Derrida, para quien el fonocentrismo define toda la metafísica, no ha visto que la relación entre escritura y lenguaje hablado en absoluto llegó a ser problemática ya en Platón, como él insinúa, sino sólo bajo las condiciones de la producción industrial, esto es, en el siglo XIX. Puesto que la escritura, en cuanto problema filosófico, es el producto técnico con la promesa de que en él se aclare la productividad humana misma, que en todos los demás productos técnicos se sustrae imprevisiblemente, hasta alcanzar una legibilidad que, allí donde la productividad se ha convertido en la esencia del hombre, tiene necesariamente que presentarse al mismo tiempo como legibilidad del mundo. Y hay que ver a Wagner como el principal representante del fonocentrismo histórico-real, porque afirmó que la voz, la phōnēe, en la figura de la música, es la esencia originariamente dada del hombre que ha dejado de ser metafísico.

Incluso eso, por cierto, a pesar de sus consecuencias, fue nada más que un momento histórico. En vista de la constelación ideológica de la Modernidad industrial en general, se podría decir que la obra de arte wagneriana, conforme a su mensaje, se ubica en el paisaje histórico entre Kierkegaard y Marx. Este último había dado la espalda al cristianismo del siglo XIX — estetizado por completo desde el romanticismo temprano, desde Chateaubriand y Lamartine- en cuanto «región nebulosa del mundo religioso», incluso en la figura feuerbachiana de la relación religosamente elevada de yo y tú, con el fin de estudiar el «conjunto de las relaciones sociales». Y si antes Kierkegaard, en vista de la pérdida de credibilidad de la metafísica, había renunciado a la posibilidad de un cristianismo de la comunidad y había concebido un cristianismo de la persona singular, por lo cual tuvo que separar estrictamente el estadio «religioso» del estadio "estético», Wagner sólo pudo intentar hacer vinculante su religión del arte identificando, por el contrario, el estadio estético y el religioso; de modo que la religión sólo debía tener lugar allí donde acontecía la obra de arte, o sea, «la obra de arte total» (Gesamtkunstwerk), por tanto, la obra de arte escénica y, eminentemente, el «festival escénico sagrado». La exigencia desesperada de Nietzsche de que «el teatro no llegue a enseñorearse de las artes», era cualquier cosa antes que el pensamiento ilusorio de un estético refinado.

Las fases históricas eran así esencialmente las siguientes: la religión como fenómeno estético-aistético (Romanticismo, Schopenhauer, Feuerbach); la separación de la esfera estética de la esfera religiosa (Kierkegaard); la identificación de estas esferas: la obra de arte como religión (Wagner); el abandono de la esfera 
del «reflejo» en general en cuanto esfera de la «superestructura» en virtud de la «base» socio-económica (Marx); el sondeo del «abismo» de esta base como abismo de las valoraciones «morales» (Nietzsche). Y aunque para la música del fin de siècle se abrió con Nietzsche una nueva fuente de inspiración (Strauss, Mahler), fue, no obstante, precisamente el pensamiento de Nietzsche el que sacó a la luz — cerrándolo así- aquel abismo abierto por Schopenhauer a partir del cual la música del siglo XIX pareció surgir con la pretensión de ser la verdad de la religión. 